\title{
Avaliação de oportunidades de produção mais limpa para a redução de resíduos sólidos na fabricação de tintas
}

\author{
Marcelo Alessandro Molinaria*, Osvaldo Luiz Gonçalves Quelhas ${ }^{\mathrm{b}}$, \\ Armando Pereira do Nascimento Filho ${ }^{c}$ \\ a*epmolinari@yahoo.com.br, UFF, Brasil \\ bquelhas@latec.uff.br, UFF, Brasil \\ 'gqiarma@vm.uff.br, UFF, Brasil
}

\section{Resumo}

Esta pesquisa procura contribuir com os avanços científicos relacionados à produção mais limpa (PmaisL) utilizando o conhecimento existente no campo dos sistemas de gestão do meio ambiente. 0 problema da pesquisa suscita o seguinte questionamento: Como reduzir as perdas de matérias-primas em pó na fabricação de tintas anticorrosivas para revestimento? Foram sugeridas três técnicas para serem avaliadas, denominadas oportunidades de PmaisL. A parte teórica do estudo permite o entendimento do conceito de PmaisL. Buscaram-se, como referência internacional, manuais desenvolvidos pela UNIDO/UNEP, e referências nacionais, manuais desenvolvidos pelo Senai/CNTL. Como método de pesquisa, optou-se pelo estudo de caso. Considerou-se relevante a elaboração do estudo de caso em uma indústria fabricante de tintas em função da natureza poluidora de suas atividades. 0 resultado deste estudo é uma ferramenta gráfica que fornece a informação visual necessária para comparar oportunidades de PmaisL em termos de custo econômico e risco ambiental.

Palavras-chave

Produção mais limpa. Ecoeficiência. Fabricação de tintas. Resíduos sólidos.

\section{Introdução}

Ao longo dos anos a demanda por matériasprimas tem crescido em ritmo acelerado. A escassez de recursos naturais em um futuro próximo é iminente caso não sejam tomadas providências para reverter essa situação. Uma parte das matérias-primas ao ser utilizada no processo produtivo torna-se resíduo, que é descartado em lixões urbanos, incinerado ou levado para aterros sanitários, o que afeta diretamente a qualidade de vida no planeta. Isso ocorre porque a quantidade de matérias-primas que entram no processo produtivo não é a mesma que sai na forma de produtos ou subprodutos, consequentemente são geradas perdas.

0 objetivo deste artigo é avaliar três oportunidades de produção mais limpa (PmaisL) para a redução dos resíduos gerados na fabricação de tintas anticorrosivas para revestimento.

A pesquisa terá como base um estudo de caso de uma fábrica de tintas no Brasil.

As vantagens da implementação de técnicas de PmaisL são significativas para todos os envolvidos: do fornecedor à empresa, da empresa aos funcionários, dos funcionários ao meio ambiente, do meio ambiente à sociedade. Mas é a empresa que obtém os maiores benefícios para seu próprio negócio.

\section{A Produção mais limpa}

As iniciativas de muitos países em criar legislações ambientais mais severas, aumentar a fiscalização por intermédio de órgãos reguladores ambientais, como 
no caso da United States Environmental Protection Agency (USEPA), encarregada da proteção da saúde humana e do meio ambiente nos Estados Unidos, e ações concretas como a criação de programas de monitoramento da qualidade do ar, poluição da água, economia de energia e geração de resíduos contribuíram para o surgimento da produção mais limpa.

As atividades voltadas à produção mais limpa passaram a ter o apoio da United Nations Environment Programme (UNEP) a partir de 1989 e tiveram como base o Relatório de Brudtland denominado "Our Common Future", publicado pela United Nations World Commission on Environment and Development (WCED) em 1987. Esse relatório faz parte de uma série de iniciativas que reafirmam uma visão crítica do modelo de desenvolvimento adotado pelos países industrializados, e reproduzido pelas nações em desenvolvimento, e que ressaltam os riscos do uso excessivo dos recursos naturais sem considerar a capacidade de suporte dos ecossistemas.

0 conceito de produção mais limpa criado pela UNEP, formalizado em sua declaração "International Declaration on Cleaner Production" de 1998, afirma que: a produção mais limpa é a aplicação contínua de uma estratégia ambiental preventiva e integrada, aplicada a processos, produtos e serviços. Incorpora o uso mais eficiente dos recursos naturais e, consequentemente, minimiza a geração de resíduos e poluição, bem como os riscos à saúde humana.

A metodologia da Pmaisl foi desenvolvida entre a UNEP e a United Nations Industrial Development Organization (UNIDO), no programa de prevenção proposto às nações em desenvolvimento, como um instrumento prático ligado à Agenda 21 da Conferência das Nações Unidas sobre o Meio Ambiente e o Desenvolvimento (CNUMAD), realizada em 1992 no Rio de Janeiro (Rio-92).

No Brasil, essa metodologia foi adaptada pelo Centro Nacional de Tecnologias Limpas (CNTL) do Serviço Nacional de Aprendizagem Industrial (Senai) e desde 1995 vem sendo utilizada.

Para o CNTL (CENTRO..., 2010), a Pmaisl é a aplicação contínua de uma estratégia econômica, ambiental e tecnológica integrada aos processos e produtos, a fim de aumentar a eficiência no uso de matérias-primas, água e energia, através da não geração, minimização ou reciclagem de resíduos gerados em um processo produtivo.

De acordo com Barbieri (2004), a PmaisL envolve produtos e processos, estabelecendo uma sequência de prioridades a ser seguida: prevenção, redução, reuso e reciclagem, tratamento com recuperação de materiais e energias, tratamento e disposição final.

Para o CNTL (CENTRO..., 2010), a prioridade da produção mais limpa está no topo e à esquerda da Figura 1: evitar a geração de resíduos e emissões (nível 1). Os resíduos que não podem ser evitados devem, preferencialmente, ser reintegrados ao processo de produção da empresa (nível 2). Na sua impossibilidade, medidas de reciclagem fora da empresa podem ser utilizadas (nível 3).

\section{Metodologia da pesquisa}

A metodologia da pesquisa, Figura 2, é uma adaptação do estudo de ecoeficiência realizado em uma indústria marroquina de tinturaria pela parceria entre

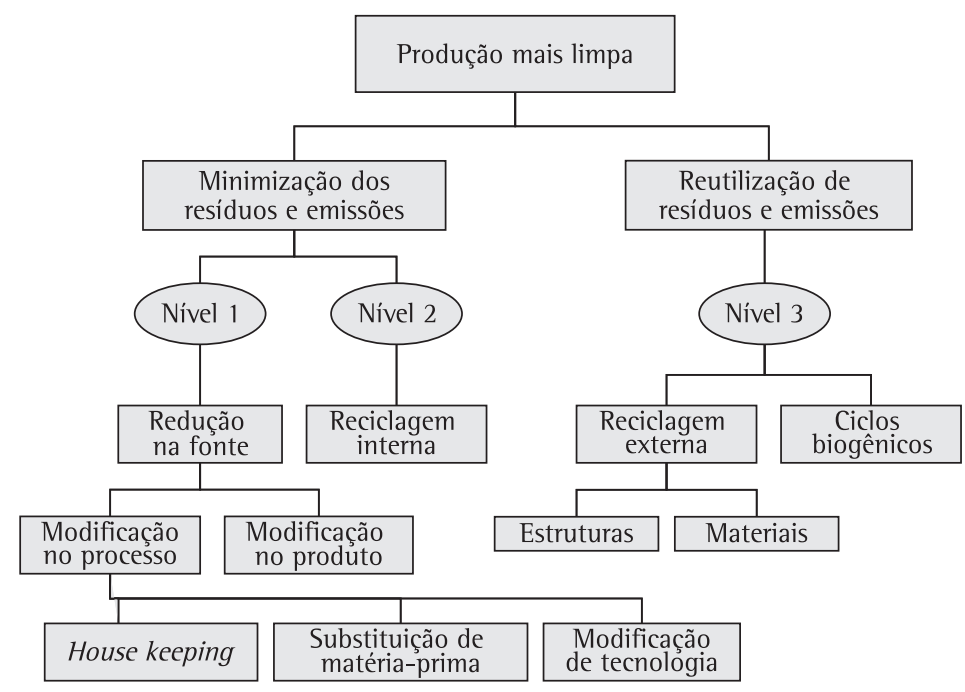

Figura 1. Fluxograma de priorização por níveis de PmaisL. Fonte: CNTL (CENTRO..., 2010). 


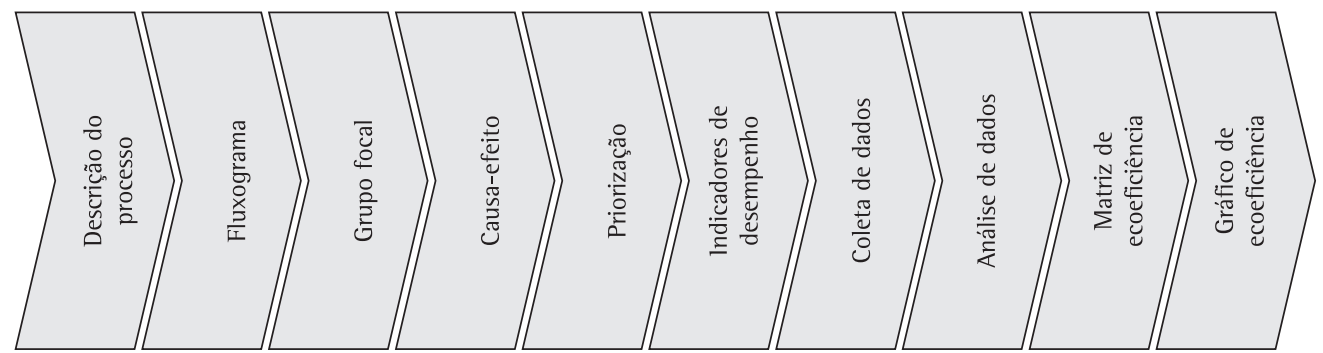

Figura 2. Diagrama da metodologia da pesquisa. Fonte: Eco-Efficiency for SMEs in the Moroccan Dyeing Industry, UNIDO (UNITED..., 2002), adaptado.

a BASF, UNIDO e a UNEP intitulado Eco-Efficiency for SMEs in the Moroccan Dyeing Industry. 0 diagrama abaixo mostra de forma sequencial as etapas seguidas para a construção do gráfico de ecoeficiência.

As etapas iniciais de descrição do processo e fluxograma procuram retratar o funcionamento da indústria e fornecer uma visão geral do processo produtivo. 0 grupo focal consiste em uma atividade para explorar a potencialidade criativa dos indivíduos, onde participantes de áreas distintas da empresa ficam reunidos e expõem suas ideias sobre um tema principal para que possam chegar a um conjunto de fatores que causam o problema a ser investigado. 0 diagrama de causa e efeito, Ishikawa (1990), ajudará a identificar as causas que levam ao problema. A priorização consiste na escolha de um ponto de partida para a investigação entre inúmeras possibilidades, restringindo assim as variáveis estudadas. Através da priorização é definida a causa principal para o problema estudado e as possíveis soluções.

Os indicadores de desempenho econômico e ambiental formarão a base de dados para a matriz de ecoeficiência que, através da soma ponderada da pontuação de cada oportunidade de PmaisL, fornecerá as coordenadas dos eixos $X$ (abscissas) relativas a custo econômico e $\mathrm{Y}$ (ordenadas) relativas a risco ambiental do gráfico de ecoeficiência.

A pontuação dos indicadores de custo econômico refletem os custos ou benefícios de cada técnica de PmaisL. A pontuação dos indicadores de risco ambiental refletem o grau de risco médio com base na maior frequência de votos de risco ambiental de cada item avaliado pelos participantes, seguindo os critérios de severidade e frequência da matriz de riscos.

0 gráfico de ecoeficiência traduz os dados da matriz de ecoeficiência em informação visual permitindo a comparação entre as diferentes oportunidades de Pmaisl estudadas.

\section{Indicadores econômicos}

Os indicadores de custo econômico foram criados a partir de objetivos de desempenho que a indústria almeja alcançar; segundo Slack et al. (2002), são divididos em: qualidade, rapidez, confiabilidade, flexibilidade e custo. Eles foram ponderados conforme pontuação obtida através de aplicação de uma matriz que avalia os parâmetros gravidade, urgência, tendência, facilidade e investimento denominada matriz GUTFl, adaptada do Programa de Excelência Gerencial do Exército Brasileiro.

A matriz GUTFl consiste em uma técnica que possibilita transformar dados qualitativos em quantitativos, permitindo traduzir a percepção dos participantes em números.

Cada uma das letras define um tipo de questão a ser avaliada conforme o Quadro 1.

\subsection{Valor presente líquido}

Para Contador (2000), ao expressar monetariamente os custos e benefícios de um projeto, se faz necessário convertê-los em termos de valor presente líquido (VPL), já que a sociedade teria que abrir mão de um benefício no presente para poder consumir no futuro, ou até mesmo para as gerações futuras. Esse método consiste em se calcular o valor presente para o fluxo de caixa (saldo de entradas e saídas) de investimento em questão, usando a taxa de juros de mercado (ou custo de oportunidade). Neste caso, se o valor encontrado for zero, significa que o retorno do investimento coincide com a taxa de juros de mercado. Caso o valor seja positivo, representa quanto a renda do investimento excede a renda esperada dada pela taxa de juros de mercado e, quando negativo, significa que a renda que o investimento proporciona é menor que o custo de oportunidade.

Para o cálculo do VPL será considerada uma taxa de desconto de 5\%, igual à taxa mínima de atratividade (TMA), ou seja, uma taxa de juros de mercado para descontar os custos e benefícios correntes, mesmo que haja o empate financeiro entre o retorno gerado na Pmaisl e o retorno de outras aplicações do mercado. 0 período de análise será de no máximo 15 anos para que um investimento em Pmaisl possa se pagar. A 
Quadro 1. Parâmetros da matriz GUTFl.

\begin{tabular}{ll}
\multicolumn{1}{c}{ Parâmetros } & Definições \\
\hline Gravidade & Refere-se ao prazo para uma tomada de acão, avaliando o tempo disponível para resolver o problema; \\
Urgência & Busca definir a proporçäo do problema no futuro, observando a causa e o potencial de o problema aumentar; \\
Tendência & deve observar o quanto é fácil de se resolver a situação; \\
Facilidade & deve avaliar qual será o gasto para resolver o problema. \\
lnvestimento & Fonte: Programa de Excelência Gerencial do Exército Brasileiro (2007).
\end{tabular}

Quadro 2. Critérios de pontuação da matriz GUTFl.

\begin{tabular}{|c|c|c|c|c|c|}
\hline Pontuação & Gravidade & Urgência & Tendência & Facilidade & Investimento \\
\hline 5 & $\begin{array}{l}\text { Os prejuízos, dificuldades } \\
\text { são extremamente graves }\end{array}$ & $\begin{array}{l}\text { É necessária uma ação } \\
\text { corretiva }\end{array}$ & $\begin{array}{l}\text { Se nada for feito a } \\
\text { situação irá piorar } \\
\text { rapidamente }\end{array}$ & $\begin{array}{l}0 \text { problema é muito } \\
\text { fácil de ser resolvido }\end{array}$ & $\begin{array}{l}\text { Não é necessário nenhum } \\
\text { investimento }\end{array}$ \\
\hline 4 & $\begin{array}{l}\text { Os prejuízos, dificuldades } \\
\text { são muito graves }\end{array}$ & Com alguma urgência & $\begin{array}{l}\text { Vai piorar em pouco } \\
\text { tempo }\end{array}$ & $\begin{array}{l}0 \text { problema é fácil de } \\
\text { ser resolvido }\end{array}$ & $\begin{array}{l}\text { Algum investimento é } \\
\text { necessário }\end{array}$ \\
\hline 3 & $\begin{array}{l}\text { Os prejuízos, dificuldades } \\
\text { são graves }\end{array}$ & 0 mais cedo possível & $\begin{array}{l}\text { Vai piorar em médio } \\
\text { prazo }\end{array}$ & $\begin{array}{l}\text { Existe alguma } \\
\text { dificuldade para } \\
\text { resolver }\end{array}$ & $\begin{array}{l}\text { Gastos de recursos além } \\
\text { do orçamento }\end{array}$ \\
\hline 2 & $\begin{array}{l}\text { Os prejuízos, dificuldades } \\
\text { são pouco graves }\end{array}$ & $\begin{array}{l}\text { Pode esperar um } \\
\text { pouco }\end{array}$ & $\begin{array}{l}\text { Vai piorar em longo } \\
\text { prazo }\end{array}$ & $\begin{array}{l}0 \text { problema é difícil } \\
\text { de ser resolvido }\end{array}$ & $\begin{array}{l}\text { Gastos que requerem } \\
\text { remanejamento de verbas }\end{array}$ \\
\hline 1 & $\begin{array}{l}\text { Os prejuízos, dificuldades } \\
\text { são sem gravidade }\end{array}$ & Não tem pressa & $\begin{array}{l}\text { Não vai piorar e pode } \\
\text { até melhorar }\end{array}$ & $\begin{array}{l}0 \text { problema é muito } \\
\text { difícil de ser resolvido }\end{array}$ & $\begin{array}{l}\text { Gastos de recursos muito } \\
\text { significativos }\end{array}$ \\
\hline
\end{tabular}

Fonte: Programa de Excelência Gerencial do Exército Brasileiro (2007).

expressão (1) será a fórmula utilizada para o cálculo do valor presente líquido.

$V P L=\sum_{t=0}^{15}\left\{B t\left[\frac{1}{(1+i)^{t}}\right]-C_{t}\left[\frac{1}{(1+i)^{t}}\right]\right\}$

onde:

- $\mathrm{B}_{t}=$ benefício

- $\mathrm{C}_{t}=$ custo

- $\mathrm{t}$ = tempo em anos $(0,1,2,3 \ldots . . .15)$

- $\mathrm{i}$ = taxa de desconto

- Se VPL > 0 projeto é considerado viável

- Se VPL $\leq 0$ projeto é inviável

\subsection{Tempo de recuperação do investimento}

As decisões sobre projetos são geralmente tomadas em meio a incertezas quanto ao futuro. Não é possivel garantir que as expectativas formadas sobre os benefícios e custos serão perfeitamente realizadas e, para algumas atividades, os erros cometidos nas expectativas serão provavelmente maiores do que em outras (CONTADOR, 2000). Nesse sentido, será feita uma análise de sensibilidade calculando o VPL novamente mudando a taxa de desconto em múltiplos de 5 até chegar aos 20\%.

0 payback descontado ou tempo de recuperação do investimento - TRI consiste no cálculo do tempo necessário à recuperação do investimento realizado, com base no fluxo de caixa dos valores trazidos ao valor presente líquido.

$$
T R I=(t) \text { quando } \quad \sum_{t=0}^{15}\left\{V P L(B t)-V P L\left(C_{t}\right)\right\} \geq 0
$$

onde:

- $\mathrm{t}$ = tempo em anos $(0,1,2,3 \ldots 15)$

- $\mathrm{B}_{t}=$ benefício

- $\mathrm{C}_{t}=$ custo

\subsection{Investimento}

Esse indicador servirá para comparar o montante de capital necessário para implementar cada técnica de Pmaisl. 0 investimento é a aplicação de recurso financeiro com a expectativa de receber algum retorno futuro superior ao aplicado, compensando inclusive as perdas de uso desse recurso durante o período de aplicação devido aos juros. Portanto, investimento é toda aplicação de dinheiro com expectativa de lucro. Nesse estudo de caso os investimentos necessários para cada oportunidade de PmaisL foram comparados.

\subsection{Razão benefício-custo}

Através da razão benefício-custo - RBC descontados (CONTADOR, 2000), é possivel utilizar 
um critério de aceitação de oportunidades de PmaisL com base nos benefícios e custos gerados.

$R B C=\sum_{t=0}^{15}\left\{B_{t}\left[\frac{1}{(1+i)^{t}}\right] \div C_{t}\left[\frac{1}{(1+i)^{t}}\right]\right\}$

onde:

- $\mathrm{B}_{t}=$ benefício

- $\mathrm{C}_{t}=$ custo

- $\mathrm{t}$ = tempo em anos $(0,1,2,3 \ldots 15)$

- $\mathrm{i}=$ taxa de desconto

- Se RBC > 1 os benefícios são maiores do que os custos

- Se RBC $\leq 1$ os benefícios são menores ou iguais aos custos

\subsection{Percentual de manutenção}

Adotou-se como premissa que o custo de manutenção é igual a 3\% do investimento, percentual médio fornecido pelos fabricantes dos equipamentos.

\section{Indicadores ambientais}

Para a avaliação qualitativa de risco ambiental foi considerado o mesmo peso na ponderação dos indicadores, pois todos os itens avaliados foram considerados importantes na mesma proporção pela empresa estudada.

0 limite do sistema para a avaliação dos riscos ambientais foram a fábrica escolhida no estudo de caso e as matérias-primas que saem do processo produtivo sem, contudo, entrar em maiores detalhes sobre o ciclo de vida do produto.

Os indicadores ambientais resultam da etapa de priorização da causa principal escolhida, que foi meio ambiente. Esses indicadores são causas secundárias que foram apontadas no diagrama de causa e efeito; são eles: lavagem com solventes; descarte de matérias-primas em aterro sanitário; queima de matérias-primas por incineração; despejo de matérias-primas no processamento.
A pontuação desses indicadores se deu com base na maior frequência de votos dos participantes, que seguiram critérios de severidade e frequência relacionados no Quadro 3.

Segundo Rego (2005), a análise de riscos é o processo que determina o impacto que um risco pode ter e a probabilidade de sua ocorrência.

Sendo assim, o risco é o produto do impacto (severidade) pela probabilidade de ocorrência (frequência), expresso pela fórmula:

$$
\sum R=\sum s \times \sum f
$$

0 grau de risco consiste na classificação dos riscos em cinco níveis: desprezível, menor, moderado, sério e crítico, conforme demonstrado no Quadro 3.

A pontuação individual do risco de cada item avaliado será dada pelo grau de risco após a aplicação dos critérios de pontuação severidade e frequência do Quadro 3.

A pontuação final de cada oportunidade de PmaisL será dada pelo grau de risco médio (G.R. médio) que consiste na soma do grau de risco individual de cada item avaliado dividido pela quantidade de itens avaliados em cada oportunidade de Pmaist.

\section{Estudo de caso da indústria de tintas}

0 estudo de caso foi realizado em uma fábrica de tintas anticorrosivas para revestimento localizada no Rio de Janeiro. A empresa vem ampliando a sua responsabilidade com o meio ambiente e por isto tem investido muito em estudos para aumentar a ecoeficiência de suas atividades. Nesse sentido, foi permitida a realização desse estudo de caso cujo foco foi definido nas perdas de matérias-primas em pó geradas na fabricação de tintas.

As matérias-primas em pó utilizadas na fabricação das tintas chegam de um fornecedor situado em São Paulo em embalagens de papelão com capacidade de carga de $10 \mathrm{~kg}$ a $40 \mathrm{~kg}$.

As perdas de matérias-primas ocorrem na pesagem, no corte dos sacos de papelão e no despejo de matérias-primas nas máquinas de processamento. Essas

Quadro 3. Critérios de pontuação de risco.

\begin{tabular}{|c|c|c|c|c|c|c|c|}
\hline \multicolumn{2}{|c|}{ Severidade } & \multirow{2}{*}{$\frac{\text { Critérios }}{\text { Desprezível }}$} & \multicolumn{2}{|c|}{ Frequência } & \multirow{2}{*}{$\frac{\text { Critérios }}{\text { Extremamente remota }}$} & \multicolumn{2}{|r|}{ Cores da matriz de risco } \\
\hline 1 & 1 & & A & 1 & & 1 & Desprezível $(1 \leq r \leq 3)$ \\
\hline 11 & 2 & Marginal & B & 2 & Remota & 2 & Menor $(4 \leq r \leq 6)$ \\
\hline 111 & 3 & Crítica & $\mathrm{C}$ & 3 & Improvável & 3 & Moderado $(7 \leq r \leq 9)$ \\
\hline \multirow[t]{2}{*}{ IV } & 4 & Catastrófica & $\mathrm{D}$ & 4 & Provável & 4 & Sério $(10 \leq R \leq 14)$ \\
\hline & & & $\mathrm{E}$ & 5 & Frequente & 5 & Crítico $(15 \leq \mathrm{R} \leq 20)$ \\
\hline
\end{tabular}


perdas são varridas do chão da fábrica, permanecem presas no interior das embalagens de papelão ou são aspiradas por um exaustor.

\section{Coleta de dados}

Com base na observação do processo de produção de tintas e nas informações fornecidas pela empresa foi possivel definir algumas premissas que são: demanda regular de 2.669,05 t de matérias-primas em pó processadas anualmente; perda de $82 \mathrm{t}$ ao ano sendo $55 \mathrm{t}$ nas embalagens de papelão, $4 \mathrm{t}$ na varrição e $23 \mathrm{t}$ no exaustor; custo anual da perda US\$ $37.348,36$; embalagens de papelão vazias totalizam $71 \mathrm{t}$ ao ano e custam US\$177.018,12; distância até o fornecedor $481 \mathrm{~km}$ do Rio de Janeiro a São Paulo; taxa de câmbio R\$ 1,8049 do Banco Central do Brasil (Bacen) em 18 de setembro de 2009.

\section{Resultados dos indicadores econômicos}

Três oportunidades de PmaisL foram avaliadas através dos indicadores de custo e benefício econômico; são elas: alteração na embalagem do fornecedor, coprocessamento e reaproveitamento de matérias-primas no processo produtivo.

Considerando os critérios de pontuação apresentados no quadro 2, 0 resultado da aplicação da matriz GUTFI para estabelecer a prioridade dos objetivos de desempenho na ponderação dos indicadores de custo econômico está apresentado na Tabela 1. 0 percentual individual dos objetivos de desempenho é o resultado do produto dos valores das colunas G-U-T-F-1 de cada um deles sobre o somatório do produto de todos os objetivos de desempenho.

Os indicadores de risco ambiental foram ponderados com pesos iguais, pois os itens avaliados foram considerados importantes na mesma proporção pela empresa.

\subsection{Análise custo-benefício (ACB) da alteração na embalagem}

A padronização das embalagens para bombonas de plástico de $25 \mathrm{~kg}$, as quais são reaproveitáveis, é uma solução que vai ao encontro dos propósitos da Pmaisl enquadrada como técnica de nível 1, redução na fonte conforme Figura 1.

Além de serem mais fáceis de manusear do que as embalagens comuns de papelão, o bocal das embalagens de plástico pode ser perfeitamente encaixado nas máquinas de produção, bastando apenas alguma adaptação simples, eliminando também os desperdícios que ocorrem por varrição e exaustão durante a produção.

0 investimento inicial necessário é de US\$ 16.518,92 para a aquisição de 2.225 bombonas que serão reutilizadas para transportar as matériasprimas. Essa quantidade é suficiente para atender uma demanda semanal regular de $222 \mathrm{t}$ de matériasprimas em pó.

Cada embalagem de $25 \mathrm{~kg}$ vazia pesa $1,25 \mathrm{~kg}$ e possui dimensões $(\mathrm{C}=25,30 \mathrm{~cm} ; \mathrm{L}=30,00 \mathrm{~cm}$; $\mathrm{H}=44,00 \mathrm{~cm})$. Com a utilização de pallets de madeira de $(\mathrm{C}=1,00 \mathrm{~m} ; \mathrm{L}=1,20 \mathrm{~m})$ as bombonas podem ser empilhadas em até quatro níveis. Dessa forma, é possível agrupar 16 bombonas em quatro níveis formando um lote de 64 bombonas.

0 espaço físico para o armazenamento dos lotes de bombonas é de no mínimo $50 \mathrm{~m}^{2}(\mathrm{C}=10,00 \mathrm{~m}$; $\mathrm{L}=5,00 \mathrm{~m}$ ), cinco colunas de quatro lotes em duas prateleiras, portanto, capacidade para 2.560 bombonas.

0 custo anual do retorno das embalagens vazias ao fornecedor é de US\$ 113.836,50 considerando o custo de transporte de 73,49 (US\$/t) pelo Índice Nacional do Custo do Transporte de Lotações (INCTL), divulgado mensalmente pela Associação Nacional do Transporte de Cargas e Logística (NTCCtLogística), baseado na média anual de 2009 para distâncias de até $800 \mathrm{~km}$. Um caminhão tipo carreta possui capacidade para transportar $26 \mathrm{t}$, que correspondem a 990 bombonas cheias e, considerando as dimensões de sua carroceria $(\mathrm{C}=14,94 \mathrm{~m} ; \mathrm{L}=2,48 \mathrm{~m} ; \mathrm{H}=2,73 \mathrm{~m})$, 1.792 bombonas vazias por viagem.

Os benefícios anuais gerados pela alteração na embalagem são de US\$381.402,70. Esse valor divide-se em: US\$ 37.348,36 correspondentes às 82 t de matérias-primas por ano que deixam de ser perdidas nas embalagens, na varrição e na exaustão; US\$177.018,12 de economia com embalagens

Tabela 1. Resultado da ponderação dos indicadores de custo econômico.

\begin{tabular}{|c|c|c|c|c|c|c|c|c|c|}
\hline $\begin{array}{l}\text { Objetivos de desempenho } \\
\text { econômico }\end{array}$ & Indicadores & G & $\mathrm{U}$ & $\mathrm{T}$ & $\mathrm{F}$ & 1 & Produto & Ordem & $\%$ \\
\hline Qualidade & Razão benefício/custo & 3 & 4 & 5 & 2 & 4 & 480 & 4 & 16 \\
\hline Rapidez & Tempo de recuperação do investimento & 4 & 4 & 5 & 2 & 5 & 800 & 2 & 27 \\
\hline Confiabilidade & Manutenção & 2 & 3 & 2 & 2 & 3 & 72 & 5 & 2 \\
\hline Flexibilidade & Investimento & 5 & 4 & 3 & 2 & 5 & 600 & 3 & 21 \\
\hline Custo & Valor presente líquido & 5 & 4 & 4 & 3 & 4 & 960 & 1 & 33 \\
\hline
\end{tabular}

Fonte: Elaboração própria. 
de papelão que não serão utilizadas, podendo ser negociada a redução desse valor do preço final do fornecedor de matérias-primas; US\$ 144.107,71 anuais economizados quando a fábrica deixa de incinerar as $82 \mathrm{t}$ de matérias-primas e as $71 \mathrm{t}$ de embalagens vazias de papelão; uma economia de US\$ 22.928,52 anuais para transportar mensalmente as perdas e as embalagens de papelão até o incinerador de terceiros, considerando o mesmo caminhão tipo carreta e o mesmo custo de transporte dado pelo INCTL.

Através da análise de sensibilidade, calculando o VPL a taxas de desconto múltiplas de 5 até chegar a 20\%, nos 15 anos considerados, foi possível verificar que o VPL permanece maior do que zero, o que indica que o projeto continua viável, o TRI permanece menor do que um ano e a RBC permanece maior do que um, o que indica que os benefícios são maiores que os custos.

\subsection{Análise custo-benefício do coprocessamento}

O coprocessamento de resíduos químicos em indústrias cimenteiras tem por objetivo o aproveitamento de matérias-primas como combustíveis nos fornos de sintese e como mistura junto ao clínquer para a produção de cimento. Produtos como resíduos de tinta em pó, resíduos oleosos, solventes, óleos usados, graxas, entre outros, possuem alto poder calorífico e podem ser utilizados para reduzir os custos de produção da indústria cimenteira e resolver o problema da destinação final de resíduos enfrentado por diversas empresas como também o da indústria de tintas pesquisada. Essa é uma solução que vai ao encontro dos propósitos da PmaisL, consistindo em uma técnica de nível 3, reciclagem externa.

0 custo anual do coprocessamento é de US\$ 35.603,08 para as $153 \mathrm{t}$ anuais, que incluem $71 \mathrm{t}$ de embalagens vazias de papelão, enviadas pela fábrica de tintas junto com as $82 \mathrm{t}$ de perdas de matérias-primas. As embalagens deverão passar por um processo de limpeza para a retirada dos resíduos e depois serão incineradas no local.

0 custo anual do transporte das embalagens com as perdas de matérias-primas para o coprocessamento é de US\$22.928,52, considerando o mesmo caminhão tipo carreta e o mesmo custo de transporte dado pelo INCTL.

Os benefícios anuais gerados no coprocessamento são de US\$ 167.036,22 sendo destes: US\$ 144.107,71 anuais economizados quando a fábrica deixa de incinerar as $82 \mathrm{t}$ de matérias-primas e as $71 \mathrm{t}$ de embalagens vazias de papelão; US\$ 22.928,52 anuais para transportar mensalmente as perdas e as embalagens de papelão até o incinerador de terceiros, que é igual ao custo de transportá-las para o coprocessamento.

Através da análise de sensibilidade, calculando o VPL a taxas de desconto múltiplas de 5 até chegar a 20\%, nos 15 anos considerados, foi possível verificar que o VPL permanece maior do que zero o que indica que o projeto continua viável, o TRI permanece menor do que um ano e a RBC permanece maior do que um, o que indica que os benefícios são maiores do que os custos.

\subsection{Análise custo-benefício do reaproveitamento de matérias-primas}

A utilização de cabine de insuflamento para gerar pressão negativa juntamente com um aspirador de pó industrial para captar e depois reintroduzir as matériasprimas no processamento é uma solução que vai ao encontro dos propósitos da PmaisL, consistindo em uma técnica de reaproveitamento de matérias-primas de nível 2, reciclagem interna.

0 investimento inicial necessário é de US\$ 95.573,16 desse valor, US\$ 93.911,02 são para a aquisição de duas cabines de insuflamento de ar para gerar pressão negativa na área de despejo de matérias-primas nas máquinas de processamento e US\$1.662,14 para a compra de um aspirador de pó industrial. Os custos anuais totalizam US\$ 81.204,96 destes, US\$ 66.873,51 são custos de incineração das 71 t de papelão e US\$ $11.464,26$ de transporte do papelão até a fábrica de incineração, considerando o mesmo caminhão tipo carreta e o mesmo custo de transporte dado pelo INCTL. 0 custo anual de manutenção é de 3\% do investimento, de acordo com o fabricante, e corresponde aos US $\$ 2.867,19$ restantes.

Os benefícios anuais gerados no reaproveitamento de matérias-primas são de US\$204.384,59, sendo destes U\$37.348,36 correspondentes às $82 \mathrm{t}$ de matérias-primas por ano que deixam de ser perdidas nas embalagens, na varrição e na exaustão; US\$ 144.107,71 anuais economizados quando a fábrica deixa de incinerar as $82 \mathrm{t}$ de matérias-primas e as 71 t de embalagens vazias de papelão; US $\$ 22.928,52$ anuais para transportar as perdas e as embalagens de papelão até o incinerador de terceiros, considerando o mesmo caminhão tipo carreta e o mesmo custo de transporte dado pelo INCTL citados anteriormente.

Através da análise de sensibilidade, calculando o VPL a taxas de desconto múltiplas de 5 até chegar a 20\%, nos 15 anos considerados, foi possível verificar que o VPL permanece maior do que zero, o que indica que o projeto continua viável, o TRI permanece 
menor do que um ano e a RBC permanece maior do que um, o que indica que os benefícios continuam maiores que os custos.

\section{Resultados dos indicadores ambientais}

0 resultado dos indicadores de risco ambiental foi dado pelo grau de risco médio de cada oportunidade PmaisL, conforme a Tabela 2. As técnicas de PmaisL foram avaliadas em termos ambientais nas possíveis causas das perdas de matérias-primas e respectivos riscos ambientais associados, que foram identificados na etapa de priorização da metodologia.
Os resultados de risco ambiental estão representados na matriz de risco de cada oportunidade de PmaisL da Figura 6.

\section{Matriz de ecoeficiência}

As pontuações dos resultados de todos os indicadores foram consolidadas na matriz de ecoeficiência, Tabela 3. Essa matriz tem como resultado as coordenadas $\mathrm{X}$ e $\mathrm{Y}$ necessárias para desenhar $\mathrm{o}$ gráfico de ecoeficiência. A coordenada do eixo $X$ (abscissa) é o resultado da soma da pontuação ponderada de todos os indicadores de custo econômico, e a coordenada Y (ordenada) é o resultado da soma

Tabela 2. Análise de dados de risco ambiental.

\begin{tabular}{|c|c|c|c|c|c|c|c|c|}
\hline Técnica PmaisL & Item & Causas & Efeitos & Risco & Freq & Sev & Risco & G.R. \\
\hline \multirow{5}{*}{ Alteração na embalagem } & 1 & Lavagem com solventes & Perda de M.P. & Contaminação da água & 4 & 4 & 16 & 5 \\
\hline & 2 & $\begin{array}{l}\text { Descarte de M.P. em aterro } \\
\text { sanitário }\end{array}$ & Perda de M.P. & Contaminação do solo & 3 & 4 & 12 & 4 \\
\hline & 3 & $\begin{array}{l}\text { Queima de M.P. por } \\
\text { incineração }\end{array}$ & Perda de M.P. & Poluição do ar & 3 & 3 & 9 & 3 \\
\hline & 4 & $\begin{array}{l}\text { Despejo de m.p. no } \\
\text { processamento }\end{array}$ & Perda de M.P. & Saúde humana & 3 & 2 & 6 & 2 \\
\hline & & & & & & & Média & 3,50 \\
\hline \multirow{5}{*}{ Co-processamento } & 1 & Lavagem com solventes & Perda de M.P. & Contaminação da água & 4 & 3 & 12 & 4 \\
\hline & 2 & $\begin{array}{l}\text { Descarte de M.P. em aterro } \\
\text { sanitário }\end{array}$ & Perda de M.P. & Contaminação do solo & 4 & 4 & 16 & 5 \\
\hline & 3 & $\begin{array}{l}\text { Queima de M.P. por } \\
\text { incineração }\end{array}$ & Perda de M.P. & Poluição do ar & 5 & 4 & 20 & 5 \\
\hline & 4 & $\begin{array}{l}\text { Despejo de M.P. no } \\
\text { processamento }\end{array}$ & Perda de M.P. & Saúde humana & 5 & 4 & 20 & 5 \\
\hline & & & & & & & Média & 4,75 \\
\hline \multirow{5}{*}{$\begin{array}{l}\text { Reaproveitamento de } \\
\text { matérias-primas }\end{array}$} & 1 & Lavagem com solventes & Perda de M.P. & Contaminação da água & 3 & 1 & 3 & 1 \\
\hline & 2 & $\begin{array}{l}\text { Descarte de M.P. em aterro } \\
\text { sanitário }\end{array}$ & Perda de M.P. & Contaminação do solo & 3 & 2 & 6 & 2 \\
\hline & 3 & $\begin{array}{l}\text { Queima de M.P. por } \\
\text { incineração }\end{array}$ & Perda de M.P. & Poluição do ar & 3 & 2 & 6 & 2 \\
\hline & 4 & $\begin{array}{l}\text { Despejo de M.P. no } \\
\text { processamento }\end{array}$ & Perda de M.P. & Saúde humana & 4 & 2 & 8 & 3 \\
\hline & & & & & & & Média & 2,00 \\
\hline
\end{tabular}

Fonte: Elaboração própria.

Tabela 3. Matriz de ecoeficiência.

\begin{tabular}{|c|c|c|c|c|c|c|c|c|c|c|c|c|c|}
\hline \multicolumn{3}{|c|}{ Matriz de ecoeficiência } & \multicolumn{5}{|c|}{ Custo econômico } & \multicolumn{4}{|c|}{ Risco ambiental } & \multicolumn{2}{|c|}{ eixos } \\
\hline & Oportunidades & PmaisL & $\bar{p}$ & $\overline{\underline{F}}$ & 异 & 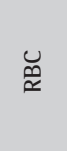 & 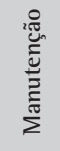 & $\underset{⿱ 乛 龰}{\mathbb{S}}$ & $\stackrel{\circ}{0}$ & $\stackrel{0}{<}$ & 岂交交 & $X$ & $\mathrm{Y}$ \\
\hline Nível & Caracteristica & Técnica & $33 \%$ & $27 \%$ & $21 \%$ & $16 \%$ & $2 \%$ & $25 \%$ & $25 \%$ & $25 \%$ & $25 \%$ & & \\
\hline 1 & Redução na fonte & $\begin{array}{l}\text { Alteração na } \\
\text { embalagem }\end{array}$ & 0,00 & 5,00 & 0,86 & 0,00 & 0,00 & 5,00 & 4,00 & 3,00 & 2,00 & 1,55 & 3,50 \\
\hline 3 & Reciclagem externa & Coprocessamento & 2,96 & 5,00 & 0,00 & 0,68 & 0,00 & 4,00 & 5,00 & 5,00 & 5,00 & 2,46 & 4,75 \\
\hline 2 & Reciclagem interna & $\begin{array}{l}\text { Reaproveitamento } \\
\text { de matérias-primas }\end{array}$ & 2,86 & 5,00 & 5,00 & 1,58 & 5,00 & 1,00 & 2,00 & 2,00 & 3,00 & 3,73 & 2,00 \\
\hline
\end{tabular}


da pontuação ponderada dos indicadores de risco ambiental de cada oportunidade de PmaisL.

\section{Gráfico de ecoeficiência}

0 gráfico de ecoeficiência da Figura 7 é o resultado dos eixos $X$ (custo econômico) e $Y$ (risco ambiental) da matriz de ecoeficiência.

\section{Discussão dos resultados}

Pelos indicadores econômicos pode-se inferir que para uma taxa mínima de atratividade (TMA) de 5\%, o maior valor presente líquido (VPL) é o da técnica de alteração nas embalagens, seguido por reaproveitamento de matérias-primas e por último 0 coprocessamento. Como o VPL das três oportunidades de Pmaisl é maior do que zero ao final do décimo quinto ano, conclui-se que os benefícios gerados para a indústria são maiores do que os custos de implementá-las.

A razão benefício-custo ( $\mathrm{RBC}$ ) das três alternativas foi maior do que um, o que demonstra que os benefícios das oportunidades de PmaisL são maiores do que os custos de implementá-las e mantê-las ao longo dos 15 anos, com destaque para a alteração nas embalagens, que superou as demais oportunidades de Pmaisl.

Com relação ao tempo de recuperação do investimento (TRI), foi verificado que em menos de um ano a receita gerada para a empresa é maior do que os custos de implementação nas três oportunidades de Pmaisl.

Nas análises de sensibilidade, Figuras 3 a 5, ao serem aplicadas diferentes TMAs, o VPL continuou maior do que zero, a RBC permaneceu maior do que um e o TRI continuou menor do que um ano para as três oportunidades de PmaisL.

As vantagens e desvantagens de cada oportunidade de Pmaisl estão descritas a seguir:

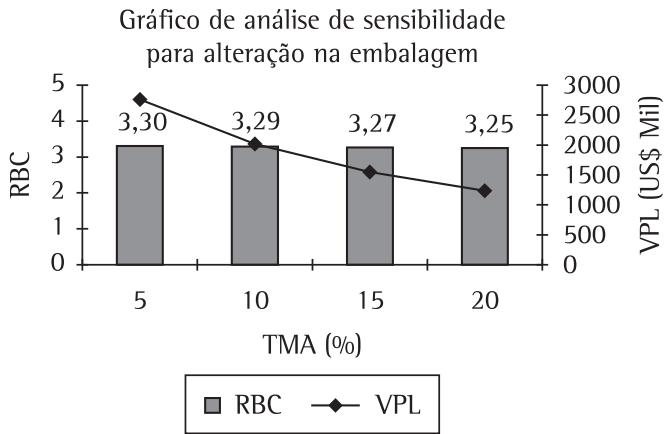

Figura 3. Gráfico de análise de sensibilidade para alteração na embalagem. Fonte: Elaboração própria.
A alteração na embalagem tem como vantagem a recuperação de matérias-primas que antes eram perdidas durante o manuseio das embalagens de papelão, porém apresenta a desvantagem de ser a técnica de maior custo de transporte para o envio das bombonas vazias ao fornecedor.

A técnica de coprocessamento tem como vantagem o custo anual menor ao que teria que ser gasto com a incineração e como desvantagem o capital perdido com o envio de matérias-primas ao coprocessamento porque essa é uma técnica de reciclagem externa, ou seja, a indústria de tintas não recupera o que foi gasto nas matérias-primas quando estas viram perdas.

0 reaproveitamento de matérias-primas tem como vantagem a recuperação daquelas que antes eram perdidas durante o manuseio das embalagens de papelão, porém apresenta a desvantagem dos altos investimentos iniciais para a aquisição dos equipamentos necessários.

Com relação ao resultado dos indicadores ambientais, o maior grau de risco ambiental foi

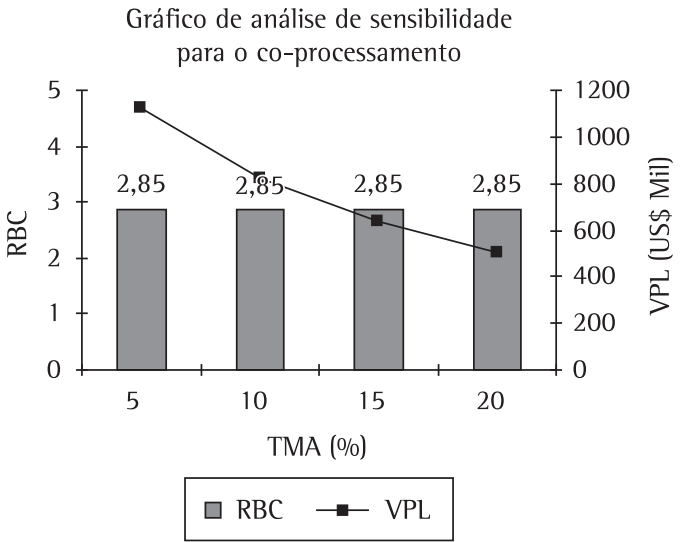

Figura 4. Gráfico de análise de sensibilidade para coprocessamento. Fonte: Elaboração própria.

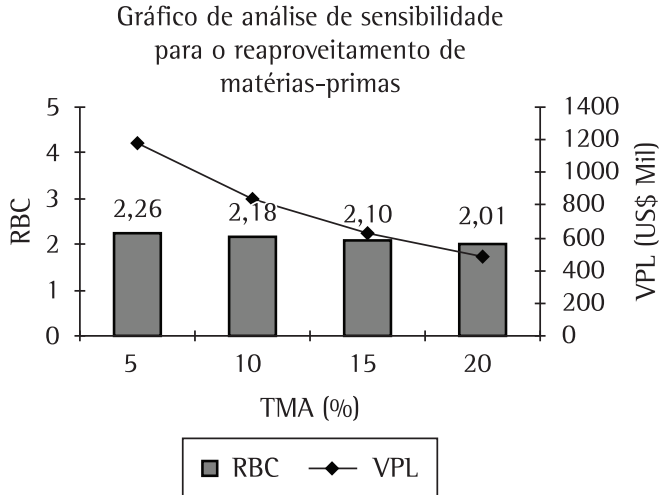

Figura 5. Gráfico de análise de sensibilidade para o reaproveitamento de matérias-primas. Fonte: Elaboração própria. 

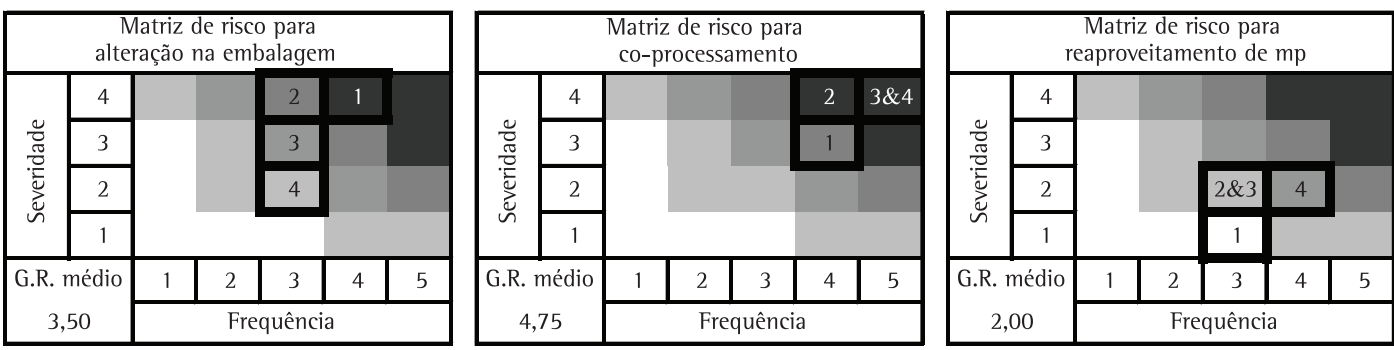

Figura 6. Matriz de risco de cada oportunidade de PmaisL. Fonte: Elaboração própria.

Gráfico de ecoeficiência

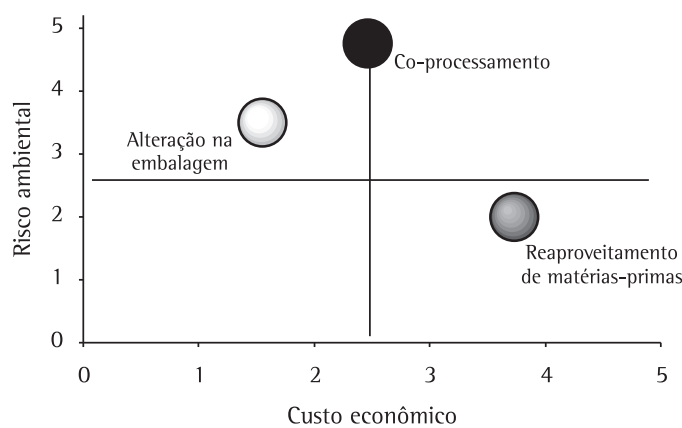

Figura 7. Gráfico de ecoeficiência. Fonte: Elaboração própria.

identificado na técnica de coprocessamento, seguido da alteração na embalagem e por último a de reaproveitamento de matérias-primas.

Também é um objetivo desta discussão uma análise crítica dos resultados obtidos, à luz do referencial teórico disponível.

As técnicas de alteração nas embalagens, reaproveitamento de matérias-primas e coprocessamento se enquadram respectivamente na sequência: redução, reuso e reciclagem, obedecendo a ordem de prioridades a serem seguidas descrita por Barbieri (2004).

Pelo fluxo de priorização por níveis de PmaisL, Figura 1, descrito pelo CNTL (CENTRO..., 2010) e Medeiros et al. (2007), a alteração nas embalagens pode ser classificada no nível 1 , redução na fonte, porque essa é uma técnica que evita a geração de resíduos, o reaproveitamento de matérias-primas pode ser classificado no nível 2, reciclagem interna, porque as matérias-primas são reintegradas ao processo de produção da empresa, e o coprocessamento pode ser classificado no nível 3, reciclagem externa, por ser esta uma medida de reciclagem fora da empresa. Os níveis, as classificações das técnicas e o resultado da pontuação dos indicadores foram apresentados na Tabela 3, matriz de ecoeficiência.

\section{Conclusões}

0 estudo de caso apresentado conclui que as perdas de matérias-primas na fabricação de tintas podem ser reduzidas através da implementação de técnicas de Pmaisl e sugere a comparação entre três delas: alteração na embalagem, coprocessamento e reaproveitamento de matérias-primas. Essas técnicas, chamadas de oportunidades de PmaisL, foram avaliadas e comparadas em termos de custo econômico e risco ambiental através de vários indicadores. Na discussão dos resultados foram apresentadas as vantagens $\mathrm{e}$ desvantagens de cada uma com base nos dados que foram coletados e analisados da fábrica de tintas estudada.

A pontuação dos resultados de todos os indicadores foi consolidada na matriz de ecoeficiência, Tabela 3, e posteriormente foi gerado o gráfico de ecoeficiência da Figura 7, que tem como objetivo fornecer uma informação visual para a comparação das oportunidades de Pmaisl.

Pelo gráfico de ecoeficiência, Figura 7, é possível perceber que a técnica de alteração na embalagem demonstrou ser a mais vantajosa de todas, já que o produto da pontuação obtida no eixo de custo econômico com a pontuação obtida no eixo do risco ambiental corresponde ao valor da menor área em relação às outras oportunidades de PmaisL do gráfico, portanto é a de menor custo econômico e menor risco ambiental.

Para a continuidade da pesquisa, poderiam ser sugeridas outras técnicas de PmaisL para serem comparadas com as que foram apresentadas. Seria interessante também a criação de critérios de ponderação dos indicadores de risco ambiental, tal como foi feito com os indicadores de custo econômico. Poderão ser considerados outros indicadores tanto em custos econômicos quanto em riscos ambientais. Outra linha de continuidade possível seria inserir modelos de previsão na variabilidade da demanda para o cálculo da quantidade necessária de embalagens para uma demanda por matérias-primas irregular. 
Sugere-se que o resultado desta pesquisa, o gráfico de ecoeficiência, possa ser utilizado como uma ferramenta de gestão para avaliar oportunidades de PmaisL, em termos de custo econômico e risco ambiental.

\section{Referências}

BARBIERI, J. C. Gestão ambiental empresarial: conceitos, modelos e instrumentos. São Paulo: Saraiva, 2004.

CENTRO NACIONAL DE TECNOLOGIAS LIMPAS - CNTL. $O$ que é Produção mais Limpa (PmaisL)? Disponível em: <http://www.senairs.org.br/cntl/>. Acesso em 02 out. 2010.

CONTADOR, C. R. Projetos sociais: avaliação e prática. 4. ed. São Paulo: Atlas, 2000.

ISHIKAWA, K. Introduction to Quality Control. Productivity Press, 1990.

MEDEIROS, D. D. et al. Aplicação da Produção mais Limpa em uma empresa como ferramenta de melhoria contínua.
Produção, v. 17, n. 1, p. 109-128, 2007. http://dx.doi. org/10.1590/S0103-65132007000100008

PROGRAMA DE EXCELÊNCIA GERENCIAL DO EXÉRCITO BRASILEIRO. Disponivel em: <http://www.exercito.gov. br/060Ms/gabcmtex/PEGEB/>. Acesso em: 02 mar. 2007.

REGO, M. A. M. Metodologia qualitativa de gestão de riscos operacionais de segurança, meio ambiente e saúde ocupacional: uma contribuição ao programa de segurança de processos. 2005. Dissertação (Mestrado Profissional em Sistemas de Gestão)-Universidade Federal Fluminense, Niterói, 2005.

SLACK, N.; CHAMBERS, S.; JOHNSTON, R. Administração da Produção. 2. ed. São Paulo: Atlas, 2002.

UNITED NATIONS INDUSTRIAL DEVELOPMENT ORGANIZATION. Eco-Efficiency for SMEs in the Moroccan Dyeing Industry (Phase I) A Sustainable Approach to Industrial Development. Vienna, 2002.

WORLD COMMISSION ON ENVIRONMENT \& DEVELOPMENT - WCED. Our Common Future: Report of the World Commission on Environment \& Development. WCED, 1987. Disponivel em: <http://www.undocuments.net/wced-ocf.htm> Acesso em: 27 set. 2011.

\title{
Evaluation of cleaner production opportunities for solid waste reduction in paint manufacturing
}

\begin{abstract}
This research seeks a contribution to scientific advances related to cleaner production (CP) using the existing knowledge in the field of environmental management systems. The following question arises from this research: "How can the loss of raw materials in anti-corrosive flooring paint production be reduced?" Three techniques, denominated CP opportunities, were suggested for evaluation. The theory of the study allows for the identification and understanding of the concept of CP. The manuals developed by UNIDO/UNEP were used as international references, while those developed by SENAI/CNTL were used as national references. The case study was chosen as research method. A case study in a paint production industry was considered relevant because of the nature of its polluting activities. Results generated a graphical tool that provides the visual information needed to compare $\mathrm{CP}$ opportunities in terms of economic costs and environmental risks.
\end{abstract}

Keywords

Cleaner production. Eco-efficiency. Paint manufacturing. Solid waste. 